\title{
The importance of follow-up gastroscopy in patients with perforated peptic ulcer
}

\author{
Perfore peptik ülser hastalarında takip endoskopisinin önemi
}

\author{
Okan Murat AKTÜRK Ф, Mikail ÇAKIR, Doğan YILDIRIM
}

\begin{abstract}
Aim: Peptic ulcer disease arises from the imbalance between the mucosal defense factors and the destructive properties of acid pepsin. The prevalance is around $5-10 \%$ of the population but only $2-10 \%$ of the patients with the disease are complicated with perforation. What is adviced is a follow up gastroscopy 6-8 weeks after the operation. We aimed to investigate gastric malignancy and helicobacter pylori prevalence in the follow-up gastroscopy.

Method: The follow-up gastroscopy notes of the patients who went under operation for perforated peptic ulcer were reviewed. The demographic properties, the operation notes, the follow-up gastroscopy notes and pathology reports were reviewed for the presence of helicobacter pylori and gastric malignancy.

Results: Between June 2014 and June 2017 a total of 132 patients were operated for peptic ulcer perforation. The average age of the patients was $43.46 \pm 18.78$ (15-93). In the study group $73.5 \%(36 / 49)$ were found to be positive for Helicobater pylori. The gastric cancer diagnosis was confirmed in 5.6\% (3/53) patients in the follow-up gastroscopy.

Conclusion: Helicobater pylori is an important factor in ethiology as well but one must be alert about the potential presence of a gastric cancer. There is also a potential malignancy presence in the perforations which are thought to be duodenal.
\end{abstract}

Keywords: Peptic ulcer perforation, gastric, cancer, helicobacter pylori öz

Amaç: Peptik ülser midedeki asit ve pepsinin yıkıcı etkileri ile mukozanın korunma faktörleri arasındaki dengesizlikten kaynaklanır. Toplumda prevalansı \%5-10 civarındadır ancak bu hastaların \%2-10 kadarı perfore olur. Genellikle önerilen operasyondan sonra 6-8 hasta içinde takip üst gastrointestinal sistem endoskopisi yapılmasıdır. Bu çalışmamızda, perfore pefore peptik ülser vakalarında takip endoskopisinde helikobakter pilori ve mide kanseri görülme sıklığını araştırdık.

Yöntem: Peptik ülser perforasyonu nedeniyle opere edilen hastaların takip endoskopileri değerlendirildi. Hastaların demografik özellikleri, operasyon notları, takip gastroskopileri ve patoloji notları değerlendirilerek hastalardaki helikobakter pilori ve gastointestinal malignansi insidansı araştırıldı.

Bulgular: Haziran 2014 ve Haziran 2017 arasında 132 hasta peptik ülser perforasyonu sebebiyle acilen operasyona alındı.

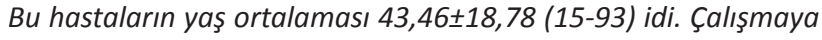
dahil edilen hastaların 36'sı (\%73,5 (36/49) takip endoskopisinde Helikobakter pilori için yapılan testte pozitif olarak bulundu. Takip endoskopisinde tanısı kesinleşen kanser insidansı \%5, 6 (3/53) olarak belirlendi.

Sonuç: Perfore peptik ülser hastalarında helikobakter pilori etiyolojide önemli rol oynamakla birlikte, mide kanseri de hastalarda etiyolojide rol oynamaktadır. Duodenal yerleşimli olduğu düşünülen perforasyonlarda da malignite olasılığı gözönünde bulundurulmalıdır.

Anahtar kelimeler: Peptik ülser perforasyonu, mide, kanser, helikobakter pilori

Received: 04.09.2018

Accepted: 18.10 .2018

Haseki Training and Research Hospital, Department of General Surgery, Istanbul, Turkey

Corresponding author: Okan Murat Aktürk, Haseki Training and Research Hospital, Department of General Surgery, Istanbul, Turkey

e-mail: omakturk@gmail.com

ORCID ID's:

O.M.A. 0000-0002-0759-3756 


\section{Giriş}

Peptik ülser hastalığı mide asidi ve pepsinin midedeki yıkıcı etkileri ve mukozanın savunma faktörleri arasındaki dengenin bozulması sonucu ortaya çıkmaktadır. Yaşam boyu toplumdaki genel prevalansı \%5-10 arasındadır ${ }^{1,2}$. Vakaların \%70'i 25 ve 64 yaş arasındadır ${ }^{3}$. Helikobakter pilori (HP) enfeksiyonu ve antiinflamatuvar ilaç kullanımı peptik ülser hastalığının sırasıyla \%48 ve \%24 gibi oranlarla en sık nedenleridir $^{4}$. Peptik ülser hastalığının en sık komplikasyonları kanama (\%73), perforasyon (\%9) ve tıkanıklıktır $(\% 3)^{5}$. Peptik ülserlerin yaklaşık \%2-10 kadarı perfore olur ${ }^{6}$. Peptik ülser perforasyonları $\% 60$ oranında duodenumun ön yüzünden kaynaklanır ve bunu \%20 oranında küçük kurvatur ülserleri takip eder; çocuklarda perforasyon nadirdir ${ }^{7}$. Geleneksel definitif peptik ülser cerrahisinden omentum pedikülü ile basit onarıma doğru bir kayma kayma olmuş ve buna proton pompası kullanımı ve HP eradikasyon tedavisi eklenmiştir ${ }^{8}$. Spontan gastrik perforasyonların bir diğer nedeni de malignansidir, mide perforasyonlarının \%10-16 kadarının mide kanserinden kaynaklanabildiği bildirilmiştir ${ }^{9}$. Spontan perforasyon gastrik kanserlerin \%1'inde görülebilen ölümcül olabilen bir komplikasyondur ${ }^{10}$. Perfore peptik ülser lezyonu birkaç milimetre boyunda, belirgin mukozal kayıp olmayan, oldukça küçük lezyonlar olabileceği gibi birkaç santime ulaşabilen büyük lezyonlarla olarak da karşımıza çıkabilirler. Perfore duodenal ülserlerde HP enfeksiyonu yüksek oranda bildirilmekle birlikte perfore peptik ülser hastalığında HP enfeksiyonunun yeri henüz net olarak açıklanmamıştır. Bu retrospektif kohort çalışmamızda, nedenler ve risk faktörlerinin tespitine yönelik olarak, perfore peptik ülser vakalarında HP ve kanser insidansı araştırılarak operasyon sonrası takip gastroskopisinin öneminin ortaya konması amaçlanmıştır.

\section{GEREÇ ve YÖNTEM}

Bu çalışma, Haziran 2014 ve Haziran 2017 arasında Sağlık Bilimleri Üniversitesi Genel Cerrahi Kliniğinde yürütülmüştür. Yerel Etik Kuruldan "Helsinki Bildirgesi"ne uygun olarak, 195/26.07.2018 no. ile izin alındıktan sonra çalışmaya başlandı. Hastanenin acil cerrahi servisine ve polikliniklerine başvuran hastalardan radyolojik ve klinik olarak perfore peptik ülser tanısı konan hastalar çalışmaya dahil edilmiştir. Hastalarda tanısal olarak klinik bulgulara ek olarak akciğer grafisi (ACG) (\%47), tanı ve ayırıcı tanı için gerekli görüldüğünde bilgisayarlı tomografi (BT) (\%53) tetkikleri uygulandı. Mortalite gelişen, 16 yaşından küçük ve gebe olan hastalar çalışmaya dahil edilmemiştir. Hastaların dosyaları incelenerek hastaların demografik özellikleri, ameliyat şekli, ameliyat bulguları, perforasyon alanının çapı ve yeri, operasyon öncesi görüntüleme sonuçları, hasta taburcu olduktan sonraki endoskopik takibi ve patoloji raporları kaydedilmiştir. Bütün hastalara acil serviste tanı konulduktan sonra sıvı ve elektrolit tedavisi verilmiştir. Kanama, mide çıkım obstrüksiyonu ya da basit kapatılma için çok büyük bir defekt olmadığı sürece yeğlenen yöntem basit kapama olmuştur. Tamirin ardından batın salin ile yıkanmıştır. Hastalar yattıkları sürece antibiyoterapi ve anti-ülser tedavi verilmiştir. Hastaneden taburculuğun ardından 8 hafta sonrası için endoskopi planlanmış ve endoskopi de ülserin iyileşme durumu ve varsa eşlik eden gastroduodenal patolojiler not edilmiştir. Bütün hastalar rutin olarak taburculuk sonrası mide endoskopisi amaçlı kontrole çağrıldığı için rutin intraoperatif biyopsi ülserlerin atipik lokalizasyonlarda olduğu ve malignite açısından şüpheli göründüğü durumlar dışında uygulanmadı. Kontrol endoskopide antral mukozadan rastgele biyopsiler alınarak HP için incelendi. Endoskopik incelemede mide mukozasından alınan örnekte HP mevcudiyetinin gösterilmesi ve patoloji raporlarında mide kanseri belirlenmesi ana bulgu olarak incelendi. Bütün istatistik analizler SPSS 22 for Windows (SPSS Inc, Chicago, IL, USA) kullanılarak yapıldı. Kantitatif değişkenler için ki-kare ve Fisher' in exact testi kullanıldı. Normal dağılımlı devamlı değişkenler için Student's t testi kullanıldı, parametrik varsayımlar karşılanmadığında Mann-Withney $U$ testi yeğlendi.

\section{BULGULAR}

Haziran 2014 ve Haziran 2017 arasında toplam 132 hasta peptik ülser perforasyonu nedeniyle acilen 
operasyona alındı. Bu hastaların yaş ortalaması 43,46 $\pm 18,78$ (15-93) idi. Hastaların \%92'si (121) erkek \%8'i (11) kadındı (Tablo 1). Ortalama yaş oranı kadınlar için $60,22 \pm 24,36$ ve erkekler için $42,24 \pm 14,82$ olarak belirlendiği, aradaki fark istatistiksel olarak anlamlı idi, $p<0,05$. Altı $(\% 4,5)$ hasta pefore peptik ülserden kaynaklanan masif kanama nedeniyle operasyona alındı. Bu hastalar peptik ülser perforasyonuna eşlik eden akut kan kaybından kaynaklanan melena, hipotansiyon ve taşikardi gibi bulguların yanısıra epigastrik ağrı ve diyafram altında serbest hava bulguları ile acil servise başvurmuşlardı. Kanamalı hastalarda perforasyon alanı duodenum ön yüzü yerleşimliydi. On $(\% 7,5)$ hasta sağlıkla ilgili komplikasyonlar yüzünden yaşamlarını kaybettiler, en sık görülen morbiditeler hipertansiyon (\%40), diyabet \%20, koroner arter hastalığı \%20, eşlik eden farklı bir sistem kanseri $\% 20$, siroz $\% 10$ olarak belirlendi. Türkiye'de ikamet eden 97 hastadan 53'ü $(\% 54,6) 2$ ay sonraki gastros-

Tablo 1. Toplamda cinsiyete göre demografik özellikler.

\begin{tabular}{lllll}
\hline $\begin{array}{l}\text { Cinsiyet } \\
\text { (sayı) }\end{array}$ & Yaş* & Kanama & Perforasyon & Mortalite \\
\hline Kadın (11) & $60+22 \pm 24,36$ & $\begin{array}{l}1 / 11 \\
(\% 9)\end{array}$ & $\begin{array}{l}10 / 11 \\
(\% 91)\end{array}$ & $\begin{array}{l}3 / 11 \\
(\% 27)\end{array}$ \\
& & & & $\begin{array}{l}7 / 121 \\
(\% 5,7)\end{array}$ \\
\hline
\end{tabular}

${ }^{*} P<0,05$, istatistiksel olarak anlamlı

Tablo 2. HP ile enfekte olan ve olmayan hastalarda perforasyon lokalizayonu.

\begin{tabular}{lllll}
\hline Perforasyon Yeri & Duodenal & Prepilorik & Corpus & Toplam: 49 \\
\hline H. pilori $(+)^{*}$ & $12(\% 33)$ & $20(\% 55 \%)$ & $4(\% 12)$ & 36 \\
H. pilori $(-)^{*}$ & $3(\% 23)$ & $8(\% 61)$ & $2(\% 15)$ & 13
\end{tabular}

*iki grup arasında perforasyon yerleşimi açısından istatistiksel olarak anlamlı farklılı yoktu, $p=0,49$ kopi kontrolüne geldi. Bu hastaların yaş ortalaması $39 \pm 15,02$ olarak bulundu. Dört hastanın yapılan tetkiklerinde H.P çalışılmamıştı ancak bu hastalar malignansi açısından negatif olarak izlendi.

Çalışmaya dahil edilen 49 hastanın 36'sı $(\% 73,5)$ takip endoskopisinde HP için yapılan testte pozitif olarak bulundu, 13 (\%26,5) hastada yapılan histopatolojik test negatif olarak bulundu. HP mevcut olan 36 hastanın operasyon notları göz önünde bulundurulduğunda 12 (\%33) hasta duodenal, 24 (\%67) hastada gastrik (4 hastada korpus, 20 hastada preopilorik ve distal antrumda) perforasyon saptandı (Tablo 2). Bizim çalışmamızda HP ile enfekte olan ve olmayan hastalar arasında perforasyon yeri açısından istatistiksel olarak anlamlı bir fak yoktu, $p=0,49$. Retrospektif olarak bakıldığında HP mevcut olan hastalarda hastanede

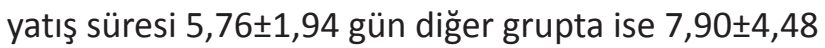
gün olarak bulundu, $p<0,05$. İki grup arasında hastanede kalış açısından anlamlı fark mevcuttu. HP negatif olan hastaların hastanede kalış süresi anlamlı olarak daha uzun olarak tespit edildi. Perforasyon çapı açısından karşılaştırıldığında HP ile enfekte olan hasta grubunda perforasyon çapı 5,83 $\pm 4,77$ milimetre $(\mathrm{mm})$, diğer grupta ise $8,22 \pm 7,03 \mathrm{~mm}(\mathrm{p}=0,65)$ olarak bulundu (Tablo 3). Bu fark istatistiksel olarak anlamlı olmamakla birlikte bunun sebebi karşılaştırma yapılan grubun görece küçük olmasından kaynaklanabilir; bu bulgu aynı zamanda HP negatif olan grubun hastanede daha uzun kalmasını açıklayabilir.

Perforasyon onarımı esnasında 2 hastada daha önceden bilinen mide kanseri tanısı mevcuttu. Bu hastaların ikisinde de rezeksiyonu mümkün olmayan mide kanseri vardı. Bu hastalar primer onarım ve omentoplastiye ek olarak gastrojejunostomi ile tedavi edildi. Diğer iki hastada tanı perforasyon alanın-

Tablo 3. HP ile enfekte olan ve olmayan iki grup arasındaki demografik, kan ve perforasyon çapı değerleri karşılaştırması.

\begin{tabular}{|c|c|c|c|c|c|c|c|}
\hline & $\begin{array}{l}\text { Yatış süresi (gün) } \\
\text { p<0,05* }\end{array}$ & $\begin{array}{l}\text { Yaş (yıl) } \\
\mathrm{p}<0,05^{*}\end{array}$ & $\begin{array}{l}\text { Çap }(\mathrm{mm}) \\
\mathrm{p}=0,65\end{array}$ & $\begin{array}{l}\text { Kreatinin }(\mathrm{mg} / \mathrm{dL}) \\
\mathrm{p}=0,35\end{array}$ & $\begin{array}{l}\text { Beyaz küre }\left(10^{\wedge} 3 u L\right) \\
p=0,06\end{array}$ & $\begin{array}{l}\text { CRP (mg/L) } \\
p=0,053\end{array}$ & $\begin{array}{l}\text { Glukoz }(\mathrm{mg} / \mathrm{DL}) \\
\mathrm{p}=0,64\end{array}$ \\
\hline H. pilori (+) & $5,76 \pm 1,94$ & $34,85 \pm 13,21$ & $5,83 \pm 4,77$ & $0,79 \pm 0,19$ & $14,80 \pm 5,37$ & $9,01 \pm 13,51$ & $138 \pm 46,71$ \\
\hline H. pilori (-) & $7,99 \pm 4,48$ & $45,63 \pm 11,85$ & $8,22 \pm 7,03$ & $1,40 \pm 1,58$ & $11,08 \pm 5,15$ & $25,53 \pm 33,10$ & $148 \pm 44,56$ \\
\hline
\end{tabular}

*istatistiksel olarak anlamlı 
da şüpheli lezyonların inspeksiyonu takiben biyopsi alınması ile konuldu. Bu hastalarda perforasyon yeri antrumda prepilorik alanda yerleşimliydi. Bu iki hasta operasyon öncesi abdominal BT'leri değerlendirildiğinde hastaların birinde antrumda difüz duvar kalınlığı bildirildiği görüldü, diğer hastanın çekilmiş olan kontrastsız tomografisinde duvar kalınlığı ile ilgili bir bulgu raporlanmamıştı. Bu hastalar daha sonra radikal total gastrektomi ve gastroenterostomi ile tedavi edildiler, her iki hasta takiben kemoterapiye yollandılar. Üç hastada takipte yapılan endoskopide alınan biyopsiler mide adenokanseri ile uyumluydu. Bir hastada mide perforasyonu ve tıkayıc tipte transvers kolon tümörü nedeniyle primer onarım ve transvers kolonda segmenter rezeksiyon uygulanmış$\mathrm{tı}$. Bu hastada preoperatif tomografide mide duvarında kalınlaşma mevcuttu, taburculuk sonrası takip gastroskopisinde mide adenocanseri tanısı kondu. Diğer hastada ise preoperatif BT'sinde ve intraoperatif bulgularında mide tümöründen şüphelenilen ve primer onarım ve omentopeksi yapılan hastanın takip endoskopisi mide adenokanseri ile uyumlu olarak geldi. Duodenal ülser perforasyonu nedeniyle primer onarım ve omentopeksi yapılan ve operasyon sırasında malignansi lehine bir bulgu saptanmayan bir hastanın takip endoskopisinde antrumdan alınan biyopsi adenokanser ile uyumlu olarak geldi. Hastanın preoperatif tomografisinde antrumda difüz kalınlaşma rapor edilmişti. Takip endoskopisinde tanısı kesinleşen 3 hasta göz önünde bulundurulduğunda operasyon sonrası dönemde tanı konan kanser insidansı \%5,6 (3/53) olarak belirlendi. Bu hastaların daha önceki biyopsileri olmadığı için HP durumları bilinmemekteydi.

\section{TARTIŞMA}

Peptik ülser perforasyonu ivedilikle tanı konması ve tedaviye başlanması gereken ciddi bir medikal durumdur. Bu hastalık gereğinde önlemler alınmazsa ve acil girişim yapılamazsa mortal seyredebilir. Peptik ülser perforasyonu insidansı dünya çapında giderek azalmakla birlikte, hala önemini koruyan bir durumdur. Helikobakter pilori duodenal ülser hastalarının \%90-100'ünde mevcut iken, gastrik ülser hastaların- da bu oran \%60-100 arasındadır ve bakterinin virulansında sitotoksin üreten bir gene veya CagA antijenine sahip olması rol oynar ${ }^{11}$. Gastroduodenal peptik ülser hastalarında mukozada HP yüksek oranda mevcut olmasına rağmen, HP ile enfekte olan bireylerin yalnızca \%10-15 kadarında peptik ülser hastalığı gelişir $^{12}$. Son zamanlarda perfore duodenal ülser için histopatolojik metotlar kullanılarak yapılan HP taramalarında bu hastalarda prevalans \%50-80 aralığında belirlenmiştir ${ }^{13,14}$.

Bizim çalışmamıza dahil edilen perfore peptik ülserli hasta grubunda HP insidansı \%67 olarak belirlenmiştir. Duodenal perforasyonu olan 16 hastanın $14(\% 87,5)$ HP histopatolojik olarak çalışılmıştı. Bu 14 hastanın 12'sinde (\%86) HP mevcut idi. Bu bulgu ülkemizde de perfore duodenal ülserlerde HP prevalansının dünya ile aynı oranda olduğuna işaret etmektedir. Çalışmaya dahil edilen toplam hasta grubunda $\% 70(37 / 53)$ oranında perforasyon gastrik düzeyde idi ve bunu takiben bulbus perforasyonu \%30 (16/53) oranı ile izlemekte idi. Bu daha önceki bazı çalışmalarla çelişmektedir. Kore'de yapılan geniş bir çalışmada, en sık perforasyon alanı duodenum bulbusu $(\% 55,1)$, pilor $(\% 25.3)$, ve antrum (\%15.7) olarak bulunmuş, toplamda duodenal ülser perforasyonunun oranı \%56,3'e karşılık \%43,7 olarak bulunmuştur. Çalışmamızda, mide perforasyonu oranı daha yüksek olarak bulunmakla birlikte, çalışmamızın retrospektif doğası gereği seçimde yanlılık olabilir, hasta sayımız da göz önünde bulunduğunda bu konuda daha geniş çaplı çalışmalara gereksinim duyulduğu açıktır ${ }^{15}$.

Dünyanın farklı ülkelerinden bu hastalıkla ilgili ciddi mortalite yüzdeleri verilmektedir. Peptik ülser operasyonlarından sonra mortalite $\% 10-25$ oranlarında bildirilmiştir ${ }^{16}$. Thorsen ve ark. ${ }^{17}$ cerrahiden sonraki 30 günlük mortalite oranını \%16 olarak belirlemişlerdir. Üç yıllık çalışmamızda, 30 günlük kısa dönem mortalite $\% 7,5$ olarak belirlenmiştir.

Duodenal ülserlerde kanser oranı neredeyse sıfır olmakla birlikte, perfore gastrik ülserlerin \%6-14'ü malign etiyolojiye sahip olabilir ${ }^{18}$. Türkiye'de 2 medikal 
merkezde yapılan 513 hastalık bir araştırmada, PUP öntanısı ile opere edilen hastalarda $67(\% 13,1)$ oranında perfore mide kanseri tanısı konduğu ve tedavi verildiği bildirilmiştir ${ }^{19}$. Bu durum non-travmatik gastroduodenal perforasyon nedeniyle başvuran hastalarda rezeksiyon ya da daha sınılı bir cerrahi yapmak arasından seçim yapmayı zorlaştırabilir.

Almanya'da yapılan başka bir çalışmada, mide kanseri tanısı ile tedavi edilen 1,273 hastalık bir seride 23 hastada perforasyon belirlendi. Acile akut gastroduodenal perforasyon nedeniyle başvuran 161 hastanın \%14'lük bir dilimini akut perfore gastrik kanser oluşturmaktaydı. Bu hasta grubunda postoperatif mortalite \%13 (3/23) olarak belirlendi. Bu hastalarda ilk tedavi olarak palyatif tedavi önerilmiştir çünkü genellikle bu hastalar radikal küratif cerrahiyi tolere edebilecek durumda değillerdir ${ }^{20}$. Laparoskopik peptik ulser perforasyonu tamiri gittikçe daha sık uygulanmaktadır. Beş yüz kırk dokuz hastalık 5 randomize kontrollü çalışmanın incelendiği bir meta-analizde, hastaların yarıdan fazlasında laparoskopik onarım uygulanmıştı. Bu çalışmaların analizinde postoperatif komplikasyonlar (ileus, pnomoni, üriner sistem enfeksiyonu, hastanede kalış düresi, onarım kaçağı, intra-abdominal apse), mortalite ve re-operasyon açısından fark görülemedi ${ }^{21}$. Hasta grubumuzda, 14 (\%11) hastalık bir grup laparoskopik olarak opere edilmiştir ve sıklığı giderek artmaktadır.

Gastrik ülser operasyonlarından sonra rutin postoperatif endoskopi mide kanseri olasılığını ekarte etmek için önerilmektedir ${ }^{22}$. Bu durum genelllikle 6-8 hafta sonrası için planlanmaktadır. Duodenal ülserlerde malignansi riski düşük olduğu için rutin gastroskopi bazı raporlarda önerilmemektedir ${ }^{23}$. Ancak akut inflamasyon ve ödemin özellikle pilora yakın lezyonlarda lokalizayonun belirsizleşmesine yol açabileceği unutulmamalıdır. Postoperatif gastroskopide kanser tanısı konan 3 hastanın operasyon notları incelendiğinde, 2 (\%67) hastada perforasyon alanının prepilorik, intraoperatif gözlemde 1'inin (\%33) duodenal kaynaklı olduğu belirtildiği görüldü. Duodenal ülserlerin genel olarak malign olarak kabul edilmediği göz önünde bulundurulduğunda, bu durum özellikle seçi- ci takip endoskopisi yapılan servislerde tanıda güçlük yaratabilir.

\section{SONUÇ}

Peripilorik anatominin çok net ortaya konamadığı ve biyopsi almanın bazen zor olabildiği durumlarda vardığımız sonuçlar rutin postoperatif gastrokopik takibin önemini ortaya koymaktadır. Bu sonuçlar giderek artan sıklıkta uygulanan laparoskopik onarımlarda daha da fazla önem gösterebilir. Postoperatif dönemde duodenal perforasyonlar dahil olmak üzere rutin gastroskopik kontrol önerilmeli ve cesaretlendirilmelidir.

\section{KAYNAKLAR}

1. Goh KL, Chan WK, Shiota S, \& Yamaoka Y. Epidemiology of Helicobacter pylori infection and public health implications. Helicobacter. 2011;16:1-9. https://doi.org/10.1111/j.1523-5378.2011.00874.x

2. Wang AY, \& Peura DA. The prevalence and incidence of Helicobacter pylori-associated peptic ulcer disease and upper gastrointestinal bleeding throughout the world. Gastrointestinal Endoscopy Clinics. 2011;21(4):613-635. https://doi.org/10.1016/j.giec.2011.07.011

3. Sonnenberg A, \& Everhart JE. The prevalence of self-reported peptic ulcer in the United States. American Journal of Public Health. 1996;86(2):200-205. https://doi.org/10.2105/AJPH.86.2.200

4. Kurata JH, \& Nogawa AN. Meta-analysis of risk factors for peptic ulcer: nonsteroidal antiinflammatory drugs, Helicobacter pylori, and smoking. Journal of clinical gastroenterology. 1997;24(1):2-17. https://doi.org/10.1097/00004836-199701000-00002

5. Wang YR, Richter JE, \& Dempsey DT. Trends and outcomes of hospitalizations for peptic ulcer disease in the United States, 1993 to 2006. Annals of Surgery. 2010;251(1):51-58. https://doi.org/10.1097/SLA.0b013e3181b975b8

6. Behrman SW. Management of complicated peptic ulcer disease. Archives of Surgery. 2005;140(2):201-208. https://doi.org/10.1001/archsurg.140.2.201

7. Ramakrishnan K, \& Salinas RC. Peptic ulcer disease. American family physician. 2007;76(7):1005-1012.

8. Nuhu A, Madziga AG, \& Gali BM. Acute perforated duodenal ulcer in Maiduguri: experience with simple closure and Helicobacter pylori eradication. West African Journal of Medicine. 2009;28(6):384-387. https://doi.org/10.4314/wajm.v28i6.55032

9. Roviello F, Rossi S, Marrelli D, De Manzoni G, Pedrazzani C, Morgagni $P, \ldots$ \& Pinto E. Perforated gastric carcinoma: a report of 10 cases and review of the literature. World Journal of Surgical Oncology. 2006;4(1):19. https://doi.org/10.1186/1477-7819-4-19

10. Kasakura Y, Ajani JA, Fujii M, Mochizuki F, \& Takayama T. Management of perforated gastric carcinoma: a report of 16 cases and review of world literature. The American Surgeon. 
2002;68(5):434.

11. Vos T, Barber RM, Bell B, Bertozzi-Villa A, Biryukov S, Bolliger I, ... \& Dicker D. Global burden of disease study 2013 collaborators. Global, regional, and national incidence, prevalence, and years lived with disability for, 301, 1990-2013.

12. Consesus Conference $\mathrm{NIH}$. Helicobacter pylori in peptic ulcer disease: NIH consensus development panel. JAMA. 1994;272:65-69. https://doi.org/10.1001/jama.1994.03520010077036

13. Gisbert JP, \& Pajares JM. Helicobacter pylori infection and perforated peptic ulcer prevalence of the infection and role of antimicrobial treatment. Helicobacter. 2003;8(3):159167. https://doi.org/10.1046/j.1523-5378.2003.00139.x

14. Reinbach DH, Cruickshank G, \& McColl KE. Acute perforated duodenal ulcer is not associated with Helicobacter pylori infection. Gut. 1993;34(10):1344-1347. https://doi.org/10.1136/gut.34.10.1344

15. Yang YJ, Bang CS, Shin SP, Park TY, Suk KT, Baik GH, \& Kim DJ. Clinical characteristics of peptic ulcer perforation in Korea. World Journal of Gastroenterology. 2017;23(14):2566. https://doi.org/10.3748/wjg.v23.i14.2566

16. Søreide K, Thorsen K, and Søreide JA. Strategies to improve the outcome of emergency surgery for perforated peptic ulcer. British Journal of Surgery. 101.1 (2014):e51-e64. https://doi.org/10.1002/bjs.9368

17. Thorsen K, Glomsaker TB, von Meer A, Søreide K, \& Søreide JA. Trends in Diagnosis and Surgical Management of Patients with Perforated Peptic Ulcer. Journal of Gastrointestinal Surgery. 2011;15(8):1329-1335.

https://doi.org/10.1007/s11605-011-1482-1

18. Leeman MF, Skouras C, \& Paterson-Brown S. The management of perforated gastric ulcers. International Journal of Surgery. 2013;11(4):322-324. https://doi.org/10.1016/j.ijsu.2013.02.010

19. Ergul E, \& Gozetlik EO. Emergency spontaneous gastric perforations: ulcus versus cancer. Langenbeck's archives of surgery. 2009;394(4):643-646. https://doi.org/10.1007/s00423-008-0331-5

20. Lehnert T, Buhl K, Dueck M, Hinz U, \& Herfarth C. Two-stage radical gastrectomy for perforated gastric cancer. European Journal of Surgical Oncology (EJSO). 2000;26(8):780-784. https://doi.org/10.1053/ejso.2000.1003

21. Tan S, Wu G, Zhuang Q, Xi Q, Meng Q, Jiang Y, ... \& Li N. Laparoscopic versus open repair for perforated peptic ulcer: $A$ meta analysis of randomized controlled trials. International Journal of Surgery. 2016;33:124-132. https://doi.org/10.1016/j.ijsu.2016.07.077

22. Leeman MF, Skouras C, \& Paterson-Brown S. The management of perforated gastric ulcers. International Journal of Surgery. 2013;11(4):322-324. https://doi.org/10.1016/j.ijsu.2013.02.010

23. Søreide K, Thorsen K, Harrison EM, Bingener J, Møller MH, Ohene-Yeboah M, \& Søreide JA. Perforated peptic ulcer. The Lancet. 2015;386(10000):1288-1298. https://doi.org/10.1016/S0140-6736(15)00276-7 